\title{
Subsídios para aquilatar a contribuição de Celso Furtado para o campo do desenvolvimento regional
}

\author{
Luis Cláudio Krajevski * \\ Tatiane Thaís Lasta ** \\ Daniel Rodrigo Strelow *** \\ Diego Boehlke Vargas **** \\ Ivo Marcos Theis $* * * * *$
}

\section{Resumo}

O objetivo do artigo é oferecer subsídios para dimensionar a contribuição de Celso Furtado à questão regional. Recorreu-se a algumas de suas obras representativas e estudos de outros autores que tratam da questão regional. Dentre os principais resultados estão que os desequilíbrios regionais em um país periférico, como o Brasil, tendem a se agravar na medida em que avançam as forças produtivas. Demonstrou que o território do país subdesenvolvido tende a se desarticular em regiões funcionais a uma inserção passiva da economia nacional, no sistema de divisão internacional do trabalho. A sua obra contribuiu para elucidar teórica e empiricamente a questão regional brasileira e apontar possibilidades concretas de sua superação.

Palavras-chave: Brasil; Celso Furtado; desenvolvimento regional.

\section{Subsidies to size the contribution of Celso Furtado to the field of regional development}

\begin{abstract}
The main purpose in this article is to offer subsidies to evaluate the contribution of Celso Furtado to the regional question. We examine some of his most representative works, as well as studies by other authors dealing with regional issues. Among the more important results is that regional disparities in a peripheral country, such as Brazil, tend to worsen with the advancement of the productive forces. Was able to demonstrate that an that the territory of the underdeveloped country tends to disintegrate into functional regions to a passive insertion of the national economy, in the international division of labor system. Celso Furtado's work contributed to elucidate theoretically and empirically the Brazilian regional question, and point out concrete possibilities for overcoming it.
\end{abstract}

Keywords: Brazil; Celso Furtado; regional development.

JEL Classification: B31; O54; R11

\footnotetext{
* Economista e Doutor pelo Programa de Pós-Graduação em Desenvolvimento Regional (PPGDR), da Universidade Regional de Blumenau (FURB), professor e pesquisador do Departamento de Economia da Universidade Federal do Paraná (UFPR). E-mail: luisck@ufpr.br

** Economista e Doutoranda do Programa de Pós-Graduação em Desenvolvimento Regional (PPGDR), da Universidade Regional de Blumenau (FURB). E-mail: tatilasta@ gmail.com

** Economista e Mestre pelo Programa de Pós-Graduação em Desenvolvimento Regional (PPGDR), da Universidade Regional de Blumenau (FURB). E-mail: danistrelow@gmail.com

**** Economista e Mestre pelo Programa de Pós-Graduação em Desenvolvimento Regional (PPGDR), da Universidade Regional de Blumenau (FURB). E-mail: vargasdb@gmail.com

***** Economista e Doutor pelo Instituto de Geografia, da Universität Tübingen (Alemanha), professor e pesquisador do Programa de Pós-Graduação em Desenvolvimento Regional (PPGDR), da Universidade Regional de Blumenau (FURB), e-mail: theis@ furb.br
} 


\section{Introdução}

Os debates envolvendo interpretações sobre a questão regional brasileira ganharam renovado fôlego nos dois primeiros decênios do século XXI. Todavia, ainda parece recorrer-se pouco ao conhecimento produzido e acumulado pelos próprios intelectuais brasileiros na busca por interpretações do Brasil, aí incluída a "questão regional”. Celso Furtado ocupou-se de numerosos aspectos referentes à formação do Brasil, entre eles, o problema das desigualdades regionais e, em consequência, a "questão regional" brasileira. Enquanto economista, diversificou seu olhar sobre o Brasil, indo muito além da ciência econômica mainstream. Alertava para os grandes deslizes, "das más abstrações, das generalizações excessivas, sobretudo as feitas pelos economistas com seus modelos entorpecentes e da busca cega para alcançar maiores graus de consistência lógica". Era crítico das abordagens que, distanciadas da realidade, orientavam as políticas públicas, assim prestando "um grande desserviço à nação" (BRANDÃO, 2013, p. 21).

Em suas obras, abarcou temas de grande amplitude, trabalhando com as mais variadas dimensões (histórica, social, política...), fornecendo elementos valiosos para a compreensão da formação espacial e regional brasileira. Sua principal obra, "Formação econômica do Brasil" (FURTADO, 1977 [1959]), na qual faz um rico e profundo diagnóstico do Brasil, é considerada por muitos estudiosos da questão regional o trabalho que inaugura as interpretações e os debates sobre o desenvolvimento regional brasileiro. Com efeito, "Formação econômica do Brasil" acabaria se firmando como obra de referência no campo do desenvolvimento regional, não havendo "qualquer produção sobre a Questão Regional que se equipare à sua produção sobre a economia brasileira. A rigor, [Celso Furtado] percebe a Questão Regional em termos de um diagnóstico" (OLIVEIRA, 1993, p. 44), um diagnóstico tão completo quanto definitivo.

Por isso, deve-se admitir que a opus magna de Celso Furtado se coloca ao lado de obras marcantes sobre as interpretações do Brasil, como: "Casa Grande e Senzala", de Gilberto Freyre, "Raízes do Brasil", de Sergio Buarque de Holanda, e "Formação do Brasil Contemporâneo", de Caio Prado Junior. Elas “explicam o Brasil aos brasileiros” (OLIVEIRA, 1983).

Celso Monteiro Furtado nasceu em Pombal, na Paraíba, em 1920, estudou Direito na Universidade do Brasil e doutorou-se na área de economia na Universidade de Paris. Em 1957 foi diretor da Divisão de Desenvolvimento Econômico da recém-criada Comissão Econômica para a América Latina e Caribe, a CEPAL. Durante este período esteve ao lado do economista argentino Raul Prebisch, participando ativamente da concepção de um enfoque estruturalista da 
realidade socioeconômica para a América Latina, visão que dominaria os trabalhos elaborados pela CEPAL.

Cabe não esquecer que Celso Furtado foi criador da Superintendência do Desenvolvimento do Nordeste, a SUDENE, em 1958, e, ainda, o primeiro titular do Ministério do Planejamento, no Brasil, entre 1962 e 1963. Cassado pelo golpe militar de 1964, acabaria vivendo na França, aí tendo sido professor de economia na Sorbonne. Após seu retorno ao Brasil, exerceu a função de ministro da Cultura entre 1986 e 1988 (D’AGUIAR, 2019).

Não é tarefa simples "construir com precisão um painel que propicie uma ideia ou balanço adequados da vasta, abrangente e profunda obra de Celso Furtado" (BRANDÃO, 2013, p. 19). Na verdade, pode-se conceder que inaugurou, involuntariamente, uma autêntica escola de pensamento. Suas ideias vêm influenciando pesquisadores de diferentes vertentes teóricas e posições políticas. A simpatia que despertou tem em mira o grande intelectual, mas também o homem público e de ação, empenhado na transformação social.

Quanto ao intelectual, a despeito da variedade de fontes de que bebeu, reconhecem-se influências que têm origem na economia e nas demais ciências sociais, em especial, na história, de correntes que vão desde o positivismo, passando pelo marxismo, até a sociologia estadunidense e a antropologia cultural. E entre os autores que mais significativamente contribuíram para a construção de seu pensamento, estão Max Weber, Karl Mannheim, John Maynard Keynes, Gunnar Myrdal, Joseph Alois Schumpeter, Raul Prebisch e François Perroux (BRANDÃO, 2013).

Considerado por muitos o principal economista brasileiro, sua obra compreende cerca de trinta livros originais, inúmeros ensaios e conferências, com tradução de alguns de seus livros em até quinze idiomas. Como já afirmado acima, o livro "Formação Econômica do Brasil" é apontado como sua obra de maior destaque. Não apenas por meio dela, seu entendimento sobre a economia e a sociedade brasileira é incontestável. Mas, não menor é o reconhecimento que auferiu em decorrência de seus achados sobre subdesenvolvimento, conceito com o qual pode explicar as mazelas do Brasil e dos demais países da América Latina.

O objetivo central deste artigo é oferecer subsídios para dimensionar a contribuição de Celso Furtado à questão regional. Para cumprir este propósito não se recorre apenas às obras do "mestre" nas quais ele desenvolve o tema - o que já se fez em outras oportunidades (ver p. ex. THEIS, 2019) -, mas também aos comentários que a elas têm sido feitos por estudiosos, sobretudo, do campo do desenvolvimento regional. Assim, a questão regional brasileira é pinçada de obras de Celso Furtado. Mas, comentadores delas são interlocutores importantes para que se logre aquilatar a contribuição do economista paraibano para o que aqui nos ocupa. 
Para cumprir com o objetivo proposto, este artigo está dividido nas seguintes seções: segue a esta introdução uma segunda seção, na qual se discorre, propriamente, sobre a questão regional; uma terceira seção, em que se contextualiza a obra de Celso Furtado e se enfatiza sua relevância para o pensamento econômico/social; uma quarta seção, em que se busca identificar a contribuição de Celso Furtado para o desenvolvimento regional; e, por fim, uma última seção, dedicada às considerações finais.

\section{Brevíssima introdução à questão regional brasileira}

As preocupações com a problemática dos desequilíbrios regionais estiveram presentes no Brasil desde o século XIX, apesar de esses não terem sido designados de "regionais". É no Nordeste e na Amazônia que apareceram as primeiras inquietações com o "regional". O Império adotaria medidas para o que hoje seriam "regiões-problema". Uma delas foi a criação da Comissão Imperial, que data de 1877. Sua função era analisar tais "regiões-problema" e propor soluções. No Nordeste, enfatizava-se a questão das secas, que assolavam violentamente a região. Já na Amazônia, era o controle do território que demandava maior atenção. É possível "que, por consequência das secas e dos problemas sociais, tenham morrido entre 100 e 200 mil pessoas" (DINIZ, 2009, p. 233; ver tb. CANO, 1998 e OLIVEIRA, 1977) apenas nos decênios finais do século XIX. Contudo, a problemática regional atrairia maior atenção apenas no século XX, sobretudo, a partir do primeiro governo de Getúlio Vargas.

Vale lembrar que, no plano internacional, no após-Segunda Guerra Mundial, uma série de políticas de reconstrução e voltadas para o desenvolvimento ganharam força. Para amparálas, instituições como o Banco Internacional para Reconstrução e Desenvolvimento (BIRD) foram criadas. Estudos sobre desenvolvimento econômico, planejamento e desenvolvimento urbano e regional também ganharam relevância. A partir do final dos anos 1940 entraria em cena a CEPAL, que logo passaria a alertar para o crescente abismo entre as nações desenvolvidas e as nações subdesenvolvidas - as primeiras cada vez mais ricas, enquanto as últimas cada vez mais pobres. Atentar-se-ia, daí em diante, para a inserção do Brasil no sistema de divisão internacional do trabalho. É neste contexto que emergiram as inquietações relacionadas à condição de subdesenvolvimento do Brasil (e de outras nações latinoamericanas) e as reflexões sobre como superá-la (CANO, 1998). A “corrente" cepalina, com sua teoria centro-periferia, passou a ter grande influência nos debates regionais no Brasil.

Aqui se pode lembrar também que, desde a década de 1920, uma ciência regional se ocupava de formular, de uma perspectiva interdisciplinar, uma concepção regionalizada de 
organização da sociedade e da economia. Entretanto, o estudo da questão espacial na economia ganharia maior fôlego somente a partir da década de 1950, aí tendo papel de relevo a difusão da teoria dos pôles de croisssance, de François Perroux. O problema tratado por Perroux (e por outros estudiosos que também se debruçavam sobre crescimento urbano e regional) dizia respeito à reorganização econômica do espaço francês. Mas, em 1954, o tema instituir-se-ia cientificamente com a criação da Regional Science Association - empreendimento bancado por Walter Isard e um grupo de mais de 60 economistas, geógrafos, cientistas políticos, sociólogos e urbanistas. O objetivo principal da Regional Science Association, que mais tarde viria se tornar a reconhecida Regional Science Association International (RSAI), era promover estudos sobre regiões, utilizando métodos e referenciais teóricos das ciências sociais e desenvolvendo instrumentos específicos à análise regional (BENKO, 1999; ISSERMAN, 2001).

A teoria dos polos de crescimento de Perroux serviu de apoio a múltiplos estudos e inspirou numerosas aplicações práticas e políticas econômicas regionais, em diversos países, nas décadas de 1950 e 1960. Tais preocupações levaram à formação, por exemplo, do quadro teórico para a formulação do conceito de desenvolvimento regional. Percebeu-se, que "o crescimento econômico não se verificava em toda parte e simultaneamente; [ele] é pontual e dinâmico e difunde-se em função da estrutura espacial e industrial da região e da armadura urbana" (BENKO, 1999, p. 78). A questão era compreender as diferenças regionais de crescimento e desenvolvimento. Ao mesmo tempo em que era uma teoria sobre o crescimento das regiões, também era uma teoria da formação das desigualdades no espaço.

Foi exatamente esse cenário do após-Segunda Guerra Mundial que inspiraria Celso Furtado a problematizar o fenômeno do subdesenvolvimento e, por conseguinte, a dinâmica das desigualdades e do desenvolvimento desigual entre as regiões; ou seja, a refletir sobre as brechas entre países desenvolvidos e subdesenvolvidos e, no interior dos últimos, entre as regiões (DINIZ, 2009).

Os esforços iniciais de Celso Furtado foram no sentido de compreender o Brasil através de sua formação histórico-econômica. Por isso, "Formação Econômica do Brasil" é considerada a mais importante contribuição do economista paraibano para o debate regional (BRANDÃO; GUIMARÃES NETO, 2009). Nela, inventariou com bastante precisão as características das economias regionais ao longo da formação do território, examinando cuidadosamente os ciclos econômicos nas regiões brasileiras: o açúcar no Nordeste; os minérios em Minas Gerais, Goiás e Mato Grosso; e o café no Sudeste (FURTADO, 1977). Sua produção intelectual posterior levá-lo-ia a conferir especial atenção para o Nordeste, o que conduziria à cocriação da SUDENE. 
Parece correto, portanto, considerar a interpretação da formação do Brasil, entre os séculos XVI e XX, em "Formação Econômica do Brasil", como uma estratégia original de identificar as condicionantes e os resultados da dinâmica econômica e demográfica sobre o território; e, por conseguinte, sua desarticulação em regiões funcionais a uma inserção passiva e subordinada do Brasil no sistema de divisão internacional do trabalho (THEIS; BUTZKE, 2019). Daí constituir-se "Formação Econômica do Brasil" em obra pioneira sobre o desenvolvimento regional brasileiro (DINIZ, 2009; GUIMARÃES NETO, 2009). A partir dela, como se verá mais à frente, Celso Furtado avançaria suas hipóteses sobre a questão regional, legando capítulos preciosos - aos estudiosos desse campo - que contêm uma reflexão potente, um argumento sofisticado que ainda não encontrou paralelo (THEIS, 2019). Aliás, caberia lembrar que:

\footnotetext{
No campo intelectual, a Questão Regional sempre foi tratada por nordestinos. Nenhum intelectual de fora do Nordeste ou da Amazônia abalançou-se a temas regionais ou à Questão Regional propriamente dita. Não há erro possível: percorra-se a bibliografia, ou frequente-se qualquer das reuniões das grandes sociedades científicas das áreas humanas e sociais, tais como ANPOCS, ABAS, SBS, SBPC. Nestas, quando se estiver tratando de algum tema regional, haverá apenas nordestinos. No caso amazônico, como a ecologia está em moda, há os verdes que são transamazônicos em sentido bem irônico e verdadeiro: eles reduzem a Amazônia a uma questão de ecologia. Ironicamente, ninguém menos que Celso Furtado não tem qualquer produção sobre a Questão Regional que se equipare à sua produção sobre a economia brasileira (OLIVEIRA, 1993, p. 44).
}

Enfim, quando a problemática regional se tornaria materialmente exigente de pensamento, emergiram tentativas de explicar as deformações no espaço socioeconômico, as disparidades inter-regionais. Ver-se-á que Celso Furtado conectaria virtuosamente o subdesenvolvimento de nações periféricas no sistema de divisão internacional do trabalho com as desarticulações internas aos seus respectivos territórios. E aí, como é sabido, a realidade regional brasileira tem se apresentado, desde o momento em que o pequeno reino lusitano tomou Pindorama por colônia até o início de século XXI, fecundíssima para toda sorte de experimentações desastradas e ensaios malsucedidos. Ver-se-á, ainda, que o economista paraibano não apenas tentou explicá-lo, identificando causas e apontando implicações, como, também, empenhou-se, com inigualável denodo, para oferecer alternativas plausíveis no quadro da institucionalidade vigente. 


\section{A obra de Celso Furtado}

Não há lugar a dúvidas quanto à importância da obra de Celso Furtado. Se já se sabe que ele formulou uma teoria do subdesenvolvimento e lançou as bases para uma teorização da questão regional, cabe acrescentar duas outras preocupações com que lidou desde cedo: o Nordeste e o Brasil. Em larga medida, seu empenho em compreender a lógica dos fluxos (socioeconômicos...) no território o conduziu a perceber a condição periférica do Nordeste numa nação periférica como o Brasil. Sua biografia ajuda a entender a devoção aos brasileiros que sofriam as agruras de um desenvolvimento regional desigual. Mas, atenção: o Nordeste era Brasil. E olhar com atenção para o Nordeste não significava desatentar para o Brasil nãonordestino. Aliás, as conexões básicas que tecera indicavam, precisamente, que o Nordeste se tornara isso que se tornara pelo fato de o Brasil ser isso que era. A preocupação de Celso Furtado com o Brasil não era, todavia, instrumental. Não se tratava de tomar o dado empírico para comprovar a hipótese. Em inúmeras de suas três dezenas de obras ele revela o seu imensurável apreço pelo país onde nasceu. Por isso, e não porque pretendia provar teses, saia à cata de evidências para questões como: Por que o Brasil, um país tão rico, é tão atrasado? Por que o Brasil, um país no qual abundam recursos, não logra suprir as necessidades mais elementares de sua população? Por que o Brasil é atrasado, inclusive se comparado a outros países da América Latina? Essas e outras questões levaram-no a mergulhar na leitura mais crítica da realidade socioeconômica brasileira (SOUSA et al., 2020a).

A obra de Celso Furtado contribuiu sobremaneira para demonstrar que a pobreza no Brasil resultava da má distribuição de renda que, por sua vez, decorria de problemas estruturais da economia do país. Neste sentido, aproximava-se do pensamento keynesiano, entendendo que o livre jogo das forças de mercado agravaria os problemas econômicos e sociais, cabendo ao Estado intervir para prover um mínimo de ordem se se quisesse perseguir alguma forma de desenvolvimento. É evidente, por exemplo, que em "Formação Econômica do Brasil" há uma combinação - virtuosa - entre teoria econômica keynesiana e análise histórica. Mas, também em outras oportunidades ele analisou criticamente a dinâmica das estruturas que moldavam o capitalismo brasileiro.

Como dito, Celso Furtado integrou os quadros da CEPAL, tornando-se um de seus principais expoentes. O estudo do subdesenvolvimento dos países da América Latina é uma das principais tarefas a que a equipe de Raul Prebisch se entregou. É daí que brota a relação centroperiferia. E o economista paraibano a absorveria para tratar das questões relacionadas ao subdesenvolvimento brasileiro. Aliás, o rigor de sua análise o levaria a constatar, surpreso, a 
existência de desigualdades maiores no Brasil que na Argentina, no México e na Venezuela. Então, ainda bem que o subdesenvolvimento era apenas uma etapa para se chegar logo mais ao desenvolvimento, não é mesmo? Bem, esta é outra descoberta, por assim dizer, que hoje parece tão óbvia a qualquer estudante de economia dos primeiros semestres. Mas, o fato é que Celso Furtado teve que mobilizar evidências e argumentos bem fundamentados para mostrar que as nações desenvolvidas nunca foram subdesenvolvidas. E que o esquema baseado no take-off tinha fragilidades insuperáveis. Os advogados do etapismo rostowiano viam apenas lógica onde, de fato, havia poder. A relação entre desenvolvidos e subdesenvolvidos se revelava uma relação centro-periferia, portanto, de dominação. Aplicado ao caso brasileiro, tinha-se que os problemas do país eram estruturais. As estruturas de poder existentes favoreciam a reprodução do subdesenvolvimento e, portanto, da concentração do poder e da renda. Para superar a condição de subdesenvolvimento seriam necessárias transformações estruturais (DINIZ, 2009, p. 237). Que também deveriam alcançar a questão regional.

\section{Desenvolvimento regional na perspectiva de Celso Furtado}

Antes de referir à contribuição teórica de Celso Furtado à questão regional, pode-se lembrar que ele teve destacada atuação enquanto homem público. Nessa condição fez pelo “desenvolvimento regional” brasileiro o que outros homens públicos não fizeram. Tome-se em consideração seus esforços para convencer seus interlocutores - como o então presidente Juscelino Kubitscheck - que as desigualdades existentes entre Sudeste e Nordeste não eram naturais, cabendo enfrenta-las com medidas governamentais, com políticas públicas; que as agruras do povo nordestino decorriam de relações de dominação vigentes na região, que beneficiavam suas elites e travavam o seu desenvolvimento; que, fundamentalmente, a seca não era um problema climático, natural, mas relativo à estrutura socioeconômica vigente.

Com essa visão de mundo procurou operar mudanças, nos quadros da institucionalidade existente, visando mitigar as desigualdades socioeconômicas no território. Poder-se-ia listar intenções e resultados em cada momento em que assumiu alguma responsabilidade pública, com destaque para os cargos de Ministro do Planejamento (Governo João Goulart), Ministro da Cultura (Governo José Sarney), Diretor Regional do Banco Nacional de Desenvolvimento Econômico-BNDE (atualmente, Banco Nacional de Desenvolvimento Econômico e SocialBNDES) e primeiro Superintendente da Superintendência do Desenvolvimento do Nordeste (SUDENE), da qual foi fundador (SOUSA et al., 2020b). 
Se sua trajetória enquanto homem público revela sua preocupação com a questão regional, esta adquire um significado especial na sua vasta produção intelectual. Se em alguns de seus textos a sua contribuição pode ser facilmente aquilatada, em outros ela tende a permanecer implícita. Contudo, com o apoio nos estudos de alguns de seus melhores comentadores se verifica uma relação inequívoca entre Celso Furtado e o desenvolvimento regional.

Ao estudar a economia brasileira ao longo da década de 1950, o economista paraibano observava que o Centro-Sul se industrializava e crescia, com destaque para São Paulo. E que as desigualdades desta região para com o Nordeste se esgarçavam. Haveria que estudar melhor o Nordeste para se entender porque não acompanhava a região socioeconomicamente mais dinâmica. Mas, haveria que estudar o Brasil, no interior do qual, afinal, tais desigualdades se manifestavam com crescente virulência. Mostrou que medidas governamentais deveriam considerar sempre o país como um todo, por exemplo, quando se desencadeia uma política de industrialização, o que evitaria a ocorrência de desequilíbrios regionais. Ademais, caberia promover uma descentralização do poder, que permitiria levar ao atendimento das necessidades das populações regionais, aspecto que deveria ser considerado quando da elaboração de um planejamento para o desenvolvimento regional (D'AGUIAR, 2013).

Ao debruçar-se sobre as desigualdades socioeconômicas do Nordeste, Celso Furtado conseguiria, de maneira exemplar, não só descrever a formação socioeconômica daquela região, como também oferecer respostas originais para o seu atraso. Como já indicado acima, adotaria a perspectiva centro-periferia da CEPAL para examinar a relação entre o Centro-Sul e o Nordeste. Essa concepção seria disseminada, posteriormente, servindo de modelo para o estudo e a análise de outras regiões - como, por exemplo, em "Formação de uma economia periférica: o caso do Paraná” (PADIS, 1981).

A peculiar perspectiva de Celso Furtado sobre o que se designa por desenvolvimento regional deriva, em grande medida, de sua análise do subdesenvolvimento, ou seja, de um desenvolvimento que produz e reproduz desigualdades também em termos geográficos. $\mathrm{O}$ Brasil como objeto de estudo privilegiado forneceria material abundante para que pudesse elucidar a problemática regional. Isso já estava suficientemente evidente em sua "Formação Econômica do Brasil”, a primeira interpretação sobre desenvolvimento regional brasileiro.

Se, como já foi mencionado, o Nordeste se constituía como a questão regional no Brasil, havia evidentemente que se conhecer seu dinamismo interno, as relações intra-regionais, mas sem olvidar das relações inter-regionais, no âmbito do território brasileiro. O famoso Relatório do Grupo de Trabalho para o Desenvolvimento do Nordeste (GTDN) parece limitar-se à órbita 
intra-regional. Mas, de fato, constitui evidência eloquente de sua capacidade de articular fatores endógenos com fatores exógenos. Se, em algum momento de sua arguta análise a industrialização assumia a condição de fator central para a promoção do desenvolvimento em escala regional, com os estímulos imprescindíveis do Estado - o que confirma a influência que a teoria keynesiana exerceu sobre o economista paraibano -, em outros ganhariam relevância novas variáveis, indicando não apenas amadurecimento intelectual, mas capacidade de aprendizado com a rica e valorosa experiência de homem público (DINIZ, 2009).

Em termos propriamente teóricos, Celso Furtado chegou a formular uma teoria das estruturas espaciais, na qual ganhariam relevo aspectos pouco tratados em textos históricoempíricos. Entre suas preocupações estavam desde as desigualdades econômicas até o crucial papel do progresso técnico. Aí propunha examinar as estruturas espaciais com maior eficácia a partir de uma abordagem interdisciplinar, portanto, não devendo a primazia caber à economia. Em termos de desenvolvimento regional, sua formulação permitiria captar a importância das mudanças espaciais a partir do ritmo de crescimento econômico regional, da distribuição das plantas industriais entre diferentes regiões, da proximidade de subsidiárias a plantas-motrizes e das próprias economias de escala resultantes (FURTADO, 1967).

De um ângulo algo distinto, pode-se ver em Celso Furtado um estudioso que reconhecia a problemática regional em períodos mais remotos da formação do Brasil. Por um lado, parece certo, como já se afirmou, que a questão regional afloraria no século XIX. Mas, por outro, também parece certo que somente no após-Segunda Guerra Mundial reconhecer-se-iam suas implicações, de maneira que apenas nesse momento ela ingressaria de forma mais explícita nas pautas do governo federal. Ela tinha um significado no contexto de um país cuja economia assentava na agricultura de exportação, que passaria a ser completamente outro no âmbito de uma nação que se industrializava. Se, antes, o dinamismo decorria da produção e exportação de café, ele passou a deslocar-se paulatinamente para a atividade substitutiva de importações. As desigualdades, em geral, e as disparidades inter-regionais, em específico, eram menores, mas ganhariam contornos assombrosos na medida em que avançavam as forças produtivas. Neste contexto de maior dinamismo impulsionado pela atividade substitutiva de importações, o Nordeste apresentava um quadro mais desfavorável - embora também se viesse a argumentar que os "desequilíbrios regionais" abarcavam todo o território brasileiro (CANO, 2000).

As desigualdades regionais brasileiras são tema recorrente na obra furtadiana. O caso do Nordeste levaria a que o economista paraibano conferisse atenção crescente para a "questão regional" brasileira. Sua percepção, informada pela experiência acumulada na CEPAL, é original, divergindo consideravelmente das concepções prevalecentes no mundo desenvolvido 
- como a da Ciência Regional. Para Celso Furtado, as desigualdades regionais tenderiam a elevar-se a partir da concentração da industrialização em São Paulo. Esta descoberta torná-loia militante do desenvolvimento regional. Como é sabido e já se o afirmou acima, após sua saída da CEPAL e seu ingresso no antigo BNDE, Celso Furtado passaria a integrar e participaria ativamente do Grupo de Trabalho para o Desenvolvimento do Nordeste (GTDN), o qual daria origem à SUDENE. Sua contribuição ultrapassaria o elenco habitual de medidas pontuais e paliativas até então adotadas. O que proporia era nada menos que a subordinação das ações governamentais e dos investimentos públicos a um planejamento atento às desigualdades regionais (CANO, 2002).

Não obstante sua militância em favor do desenvolvimento regional, sua disposição de num ambiente de respeito às instituições - apresentar respostas factíveis para os problemas relativos aos desequilíbrios socioeconômicos no território, recorrendo ao planejamento regional, os limites próprios ao contexto periférico no qual buscava se mover acabaram se lhe impondo. Questionou a política de industrialização brasileira do presidente Juscelino Kubitschek porque beneficiava, a olhos vistos, a indústria (de capital estrangeiro) instalada no Sudeste. Argumentava, corretamente, que ela não apenas manteria intactos os já graves desequilíbrios regionais acumulados, mas produziria outros ainda maiores. Como se tem lembrado, sua militância o levaria a elaborar o melhor diagnóstico que se conhece sobre a questão regional brasileira, com a indicação de alternativas concretas e viáveis para o seu enfrentamento. Tudo isso, porém, não freou a tendência - que tão perspicazmente constatou e tão bravamente combateu - à reprodução das desigualdades regionais.

Se se pode admitir que em certos períodos, uns mais longos, outros mais curtos, a referida tendência foi contida, seja pela ação estatal (por exemplo, orientando investimentos), seja por outras circunstâncias, é incontestável que o vaticínio furtadiano permaneceria teimosamente atual: o avanço das forças produtivas, ao invés de mitigar, tende a ampliar as disparidades inter-regionais. E isso fica evidente quando em sua análise assume a perspectiva, também já referida, de combinar a dinâmica interna à região com a totalidade da qual a mesma faz parte. Ao examinar a questão nacional, Celso Furtado constatou que ela não estaria resolvida caso perdurassem desequilíbrios em escala subnacional (ARAÚJO, 2000; BRANDÃO, 2010).

Este insight já se insinuava em texto publicado antes de "Formação Econômica do Brasil" vir a público. Com efeito, ele já notara previamente que a questão regional brasileira não poderia ser dissociada do conjunto; as desigualdades socioeconômicas no território não poderiam ser desconectadas da preocupação com a integridade e o desenvolvimento da nação; afinal, o Nordeste fazia parte do Brasil. Aí Celso Furtado formularia um argumento, 
amadurecido em publicações posteriores, que tomaria em conta as vicissitudes da regionalização da economia brasileira e a tendência aos desequilíbrios regionais. Seu diagnóstico era de que a economia brasileira não se encontrava, naquela quadra da história, devidamente integrada. Por isso se manifestavam disparidades no seu crescimento, com esgarçamento progressivo no nível de renda entre as regiões (FURTADO, 2012 [1958]). Aí se lhe desvelava uma das regras do capitalismo: o desenvolvimento desigual. Em face desse diagnóstico, e a partir de cuidadoso planejamento, proporia investimentos mais expressivos em regiões mais fragilizadas - que propiciariam efeitos positivos, inclusive para outras regiões - e uma adequada política de colonização para otimizar o emprego da força de trabalho e dos recursos disponíveis. Que suas principais recomendações tenham sido desconsideradas, isso ficaria evidente na permanência dos problemas sobre os quais se debruçou (ARAÚJO; SANTOS, 2009; BRANDÃO; GUIMARÃES NETO, 2009; GUIMARÃES NETO, 2009).

O homem público ético e responsável está indissociavelmente ligado ao estudioso arguto e sério quando se perscruta o aportar de Celso Furtado ao campo do desenvolvimento regional. A síntese que se poderia declinar, revisada sumariamente sua vasta obra, que tem contribuição considerável para decifrar a questão regional brasileira, é de que lhe era impensável examinar a parte desconectada do todo. E aqui poderia ser trazida à superfície, mesmo que rapidamente, a condicionante política: o enfrentamento da problemática regional passava por uma construção cuidadosa que tivesse um projeto nacional como referência inamovível (BRANDÃO, 2010). A boa notícia é que essa lição seria captada por integrantes das novas gerações de estudiosos da questão regional (GUIMARÃES NETO, 2009; SOUSA et $a l ., 2020$ c). Estas se revelam em uma interessante produção intelectual - em grande parte, vinculada à programas de pós-graduação em desenvolvimento regional - que abarca desde estudos de caráter conjuntural até detalhadas análises das diferenças geográficas, que têm em comum a boa inspiração da obra furtadiana sobre a questão regional brasileira (BRANDÃO; GUIMARÃES NETO, 2009).

\section{Considerações finais}

Pretendeu-se neste artigo oferecer subsídios para dimensionar a contribuição de Celso Furtado à questão regional. Para lograr este objetivo não se recorreu apenas às suas obras (nas quais desenvolveu o tema), mas também aos comentários que a elas foram feitos por outros estudiosos, sobretudo, daqueles ligados ao campo do regional. 
Um primeiro ponto que cumpre lembrar é que Celso Furtado se ocupou de diversos assuntos. Entre esses está, por exemplo, o do subdesenvolvimento, que do economista paraibano mereceu um grande esforço de teorização. Em termos empíricos, o Brasil e a América Latina ofereceram-lhe matéria-prima abundante, permitindo-lhe comprovar suas hipóteses e refinar sua análise.

Um segundo ponto é que, a despeito de seu ecletismo, acabaria se tornando um "clássico". Ou seja: bastaria "Formação Econômica do Brasil" para se colocá-lo ao lado dos demais grandes intérpretes do chamado Pensamento Social Brasileiro, como Gilberto Freyre, Sergio Buarque de Holanda e Caio Prado Junior. Poder-se-ia acrescentar que, com tudo o mais que publicou ao longo de sua prolífica vida, contribuiu para explicar o Brasil, a partir de uma perspectiva brasileira e para os próprios brasileiros - embora não-brasileiros também devessem ter acesso à sua precisa e elegante explicação.

O terceiro ponto, que aqui tem maior significação, é que - contrariando a Francisco de Oliveira (1983, p. 16), para quem "teoricamente, a contribuição de Celso Furtado sobre a questão regional não é muito relevante" - consideramos que sua obra tem tido importância crucial para o desvelamento da questão regional brasileira. A começar por "Formação Econômica do Brasil”, em que realiza uma impecável interpretação dos ciclos econômicos em face de seus respectivos contextos regionais. Mais tarde, em um conjunto de publicações, ele formularia e amadureceria um argumento sólido para a questão regional e seus desequilíbrios socioeconômicos. Apesar de, muitas vezes, conferir destaque ao caso nordestino, seus estudos permitem traçar paralelos e similitudes com outras regiões brasileiras.

Um quarto ponto ao qual ainda cabe atentar é que, embora tenha, com maior frequência, se limitado a examinar a questão regional como um objeto da economia, é inquestionável sua preocupação com uma totalidade jamais cingida à disciplina que o notabilizou. Celso Furtado não respeitou as fronteiras disciplinares, ocupando-se, em diversas obras, com problemas relativos ao meio ambiente, à cultura e à política, dentre outros. Que tais problemas precisem ser devidamente integrados em uma análise global do desenvolvimento regional, este é um desafio que está posto para os estudiosos do campo que tomam a obra furtadiana por referência.

Que chegue o tempo em que as desigualdades regionais sejam, no Brasil e no mundo, coisa do passado. Aí a obra de Celso Furtado ter-se-á tornado mero testemunho de que, em tempos idos, uma certa "questão regional" preocupava os seres humanos, um testemunho, enfim, de que havia para ela não apenas explicação razoável, mas também alternativa possível. 


\section{Referências}

ARAÚJO, T. B. “A ‘questão regional' e a 'questão nordestina"”. In: TAVARES, M. C. (Org.) Celso Furtado e o Brasil. São Paulo: Ed. Fund. Perseu Abramo, 2000, p. 71-92.

ARAÚJO, T. B.; SANTOS, V. M. "Desigualdades regionais e Nordeste em Formação Econômica do Brasil". In: ARAUJO, T. P.; VIANNA, S. W.; MACAMBIRA, J. (Org.) 50 Anos de Formação Econômica do Brasil: ensaios sobre a obra clássica de Celso Furtado. Rio de Janeiro: IPEA, 2009, p. 177-200.

BENKO, G. A ciência regional. Oeiras: Celta, 1999.

BRANDÃO, C.; GUIMARÃES NETO, L. A Formação Econômica do Brasil e a questão regional. In: COELHO, F. S.; GRANZIERA, R. G. (Org.) Celso Furtado e a Formação Econômica do Brasil: edição comemorativa dos 50 anos de publicação: 1959-2009. São Paulo: Atlas, 2009.

BRANDÃO, C. Desenvolvimento nacional, políticas regionais e o poder de decisão segundo Celso Furtado. Cadernos do Desenvolvimento, vol. 5, n. 7, p. 101-115, 2010.

BRANDÃO, C. "Prefácio". In: D’AGUIAR, R. F. Essencial Celso Furtado. São Paulo: Companhia das Letras, 2013, p. 19-31.

CANO, W. Desequilíbrios regionais e concentração industrial no Brasil, 1930-1995. 2 ed. Campinas/SP: Unicamp/IE, 1998.

CANO, W. Celso Furtado e a questão regional no Brasil. In: TAVARES, M. C. (Org.) Celso Furtado e o Brasil. São Paulo: Ed. Fund. Perseu Abramo, 2000, p. 93-120.

CANO, W. Ensaios sobre a formação econômica regional do Brasil. Campinas: Ed. UNICAMP, 2002.

D’AGUIAR, R. F. “Apresentação”. In: D’AGUIAR, R. F. Essencial Celso Furtado. São Paulo: Companhia das Letras, 2013, p. 7-18.

D’AGUIAR, R. F. Celso Furtado: diários intermitentes, 1937-2002. São Paulo: Companhia das Letras, 2019.

DINIZ, C. C. Celso Furtado e o desenvolvimento regional. In: Revista Nova Economia, vol. 19, n. 2, 2009, p. 227-249.

FURTADO, C. Intra-country discontinuities: toward a theory of spatial structures. Social Science Information, vol. 6, n. 6, p. 7-16, 1967.

FURTADO, C. Formação econômica do Brasil. 15 ed. São Paulo: Nacional, 1977.

FURTADO, C. Perspectivas da economia brasileira. Rio de Janeiro: Centro Internacional Celso Furtado de Políticas para o Desenvolvimento, 2012 [1958].

GUIMARÃES NETO, L. “Itinerário de Celso Furtado até Formação Econômica do Brasil”. In: ARAÚJO, T. P.; WERNECK VIANNA, S. T.; MACAMBIRA, J. (Org.) 50 anos de Formação 
Econômica do Brasil: ensaios sobre a obra clássica de Celso Furtado. Rio de Janeiro: Ipea, 2009 , p. $247-270$.

ISSERMAN, A. "Regional science". In: SMELSER, Neil J.; BALTES, Paul B. (Org.) International Encyclopedia of the Social \& Behavioral Sciences. Oxford: Elsevier, 2001, p. 12.930-12.935.

OLIVEIRA, F. Elegia para uma re(li)gião: Sudene, Nordeste, planejamento e conflito de classes. Rio de Janeiro: Paz e Terra, 1977

OLIVEIRA, F. “A navegação venturosa”. In: OLIVEIRA, Francisco de (Org.) Celso Furtado: economia. São Paulo: Ática, 1983, p. 7-27.

OLIVEIRA, F. A questão regional: a hegemonia inacabada. Estudos Avançados. vol. 7, n. 18, p. 43-63, 1993.

PADIS, P. C. Formação de uma economia periférica: o caso do Paraná. São Paulo: Hucitec, 1981.

SOUSA, C. M.; THEIS, I. M.; ALBINO B., J. L. (Org.) Celso Furtado: a esperança militante (vol. 1, Interpretações). Campina Grande: EDUEPB, 2020a.

SOUSA, C. M.; THEIS, I. M.; ALBINO B., J. L. (Org.) Celso Furtado: a esperança militante (vol. 2, Depoimentos). Campina Grande: EDUEPB, $2020 \mathrm{~b}$.

SOUSA, C. M.; THEIS, I. M.; ALBINO B., J. L. (Org.) Celso Furtado: a esperança militante (vol. 3, Desafios). Campina Grande: EDUEPB, 2020c.

THEIS, I. M. O que é desenvolvimento regional? Uma aproximação a partir da realidade brasileira. Redes, vol. 24, n. 3, p. 334-360, 2019.

THEIS, I. M.; BUTZKE, L. Desarrollo regional desigual e inserción internacional subordinada: el caso de Brasil. DAAPGE, vol. 19, n. 33, p. 31-50, 2019. 